Supporting Information

\title{
Prevention of Transition Metal Dichalcogenide Photodegradation by Encapsulation with h-BN Layers
}

Seongjoon Ahn, ${ }^{,} \S$ Gwangwoo Kim, ${ }^{\dagger}$ § Pramoda K. Nayak, ${ }^{\dagger}$ § Seong In Yoon, ${ }^{\dagger}$ §

Hyunseob Lim, ${ }^{,} \S » \|$ Hyun-Joon Shin, ${ }^{\perp}$ and Hyeon Suk Shin ${ }^{\dagger} \ddagger$, $» \| *$

†Department of Energy Engineering, ‡Department of Chemistry, §Low Dimensional

Carbon Materials Center, and $\|$ Center for Multidimensional Carbon Materials, Institute of

Basic Science, Ulsan National Institute of Science and Technology (UNIST), UNIST-gil 50,

Ulsan 689-798, Republic of Korea

${ }^{\perp}$ Beam Line Division, Pohang Accelerator Laboratory, POSTECH, Pohang 790-784,

Republic of Korea

*E-mail: shin@ unist.ac.kr 
(a)

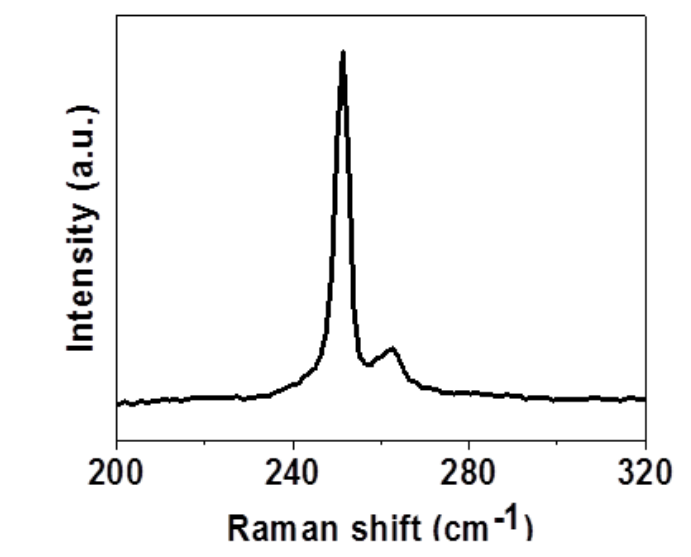

(c)

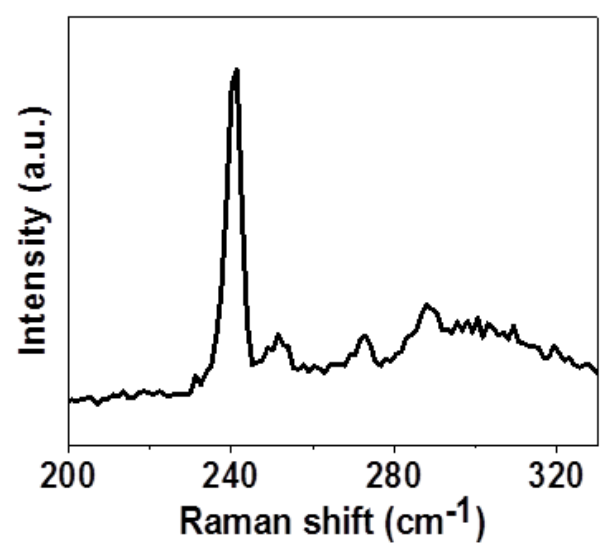

(b)

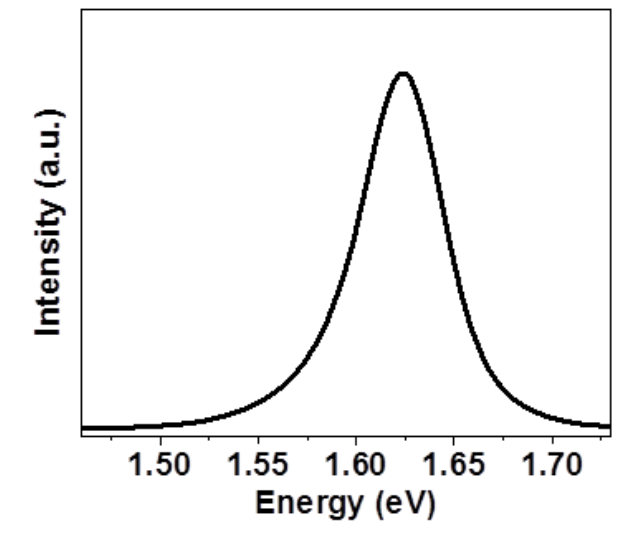

(d)

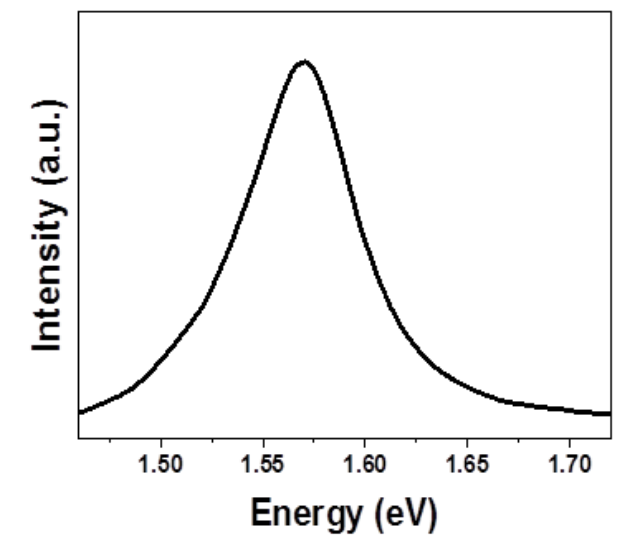

Figure S1. (a) Raman spectrum and (b) PL spectrum of the prepared $\mathrm{WSe}_{2}$. (c) Raman spectrum and (d) PL spectrum of the prepared $\mathrm{MoSe}_{2}$. 
(a)

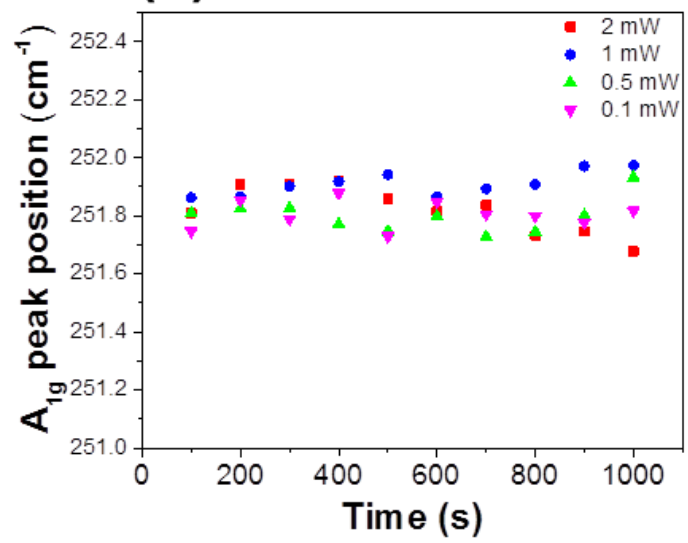

(b)

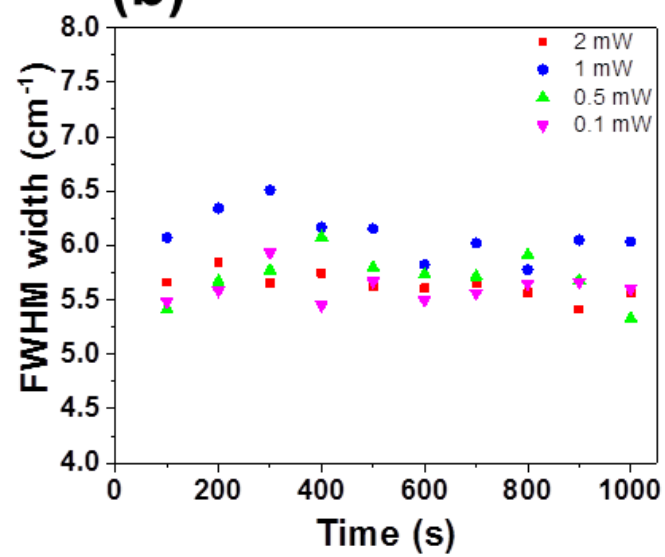

Figure S2. (a) Change in $\mathrm{A}_{1 \mathrm{~g}}$ peak position and (b) change in the FWHM in the Raman spectra of $\mathrm{WSe}_{2}$ at various laser powers as a function of exposure time. 
(a)

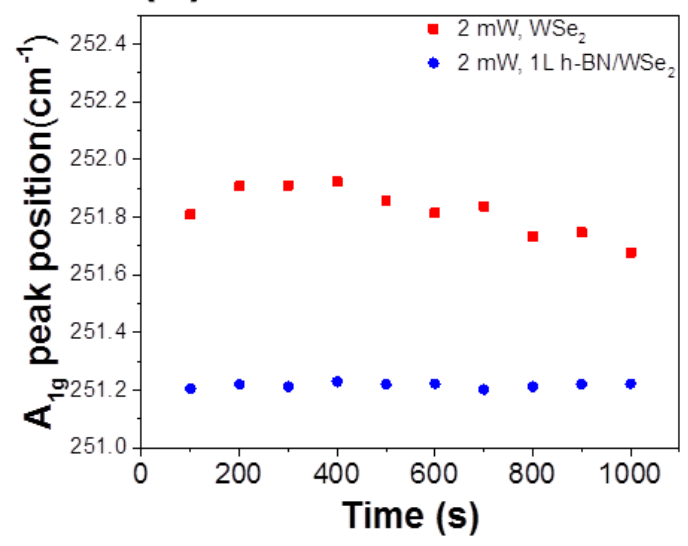

(b)

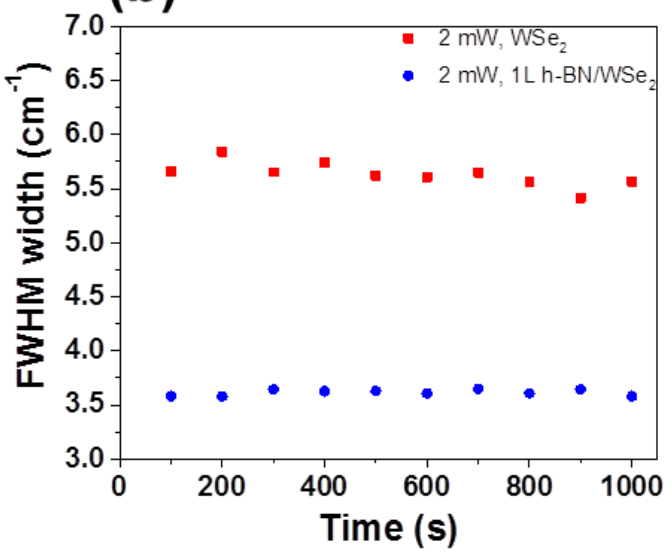

Figure S3. (a) Change in $A_{1 g}$ peak position and (b) change in the FWHM in the Raman spectra of $\mathrm{WSe}_{2}$ and $1 \mathrm{~L} \mathrm{~h}-\mathrm{BN} / \mathrm{WSe} \mathrm{S}_{2}$ at $2 \mathrm{~mW}$ as a function of exposure time. 
(a)

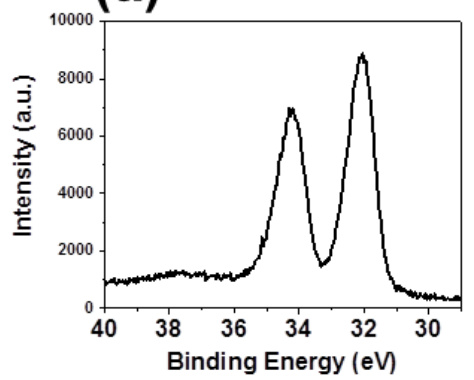

(d)

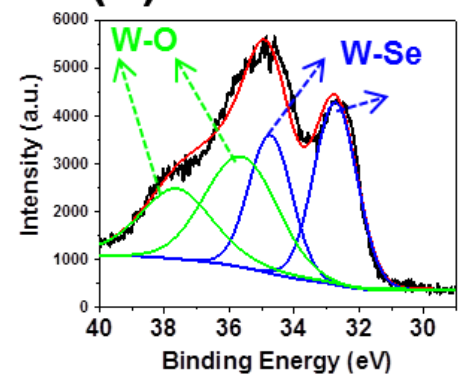

(b)

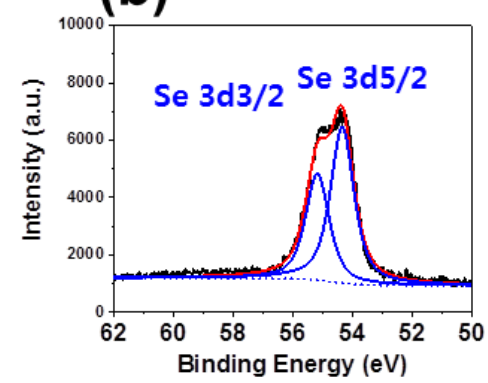

(e)

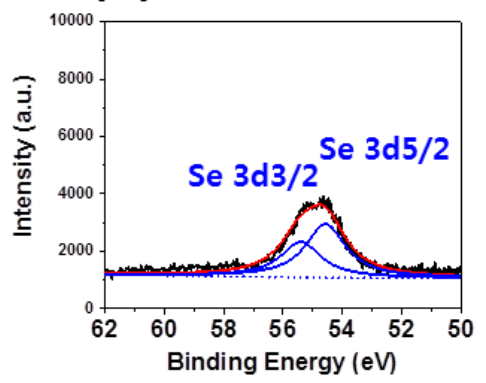

(c)

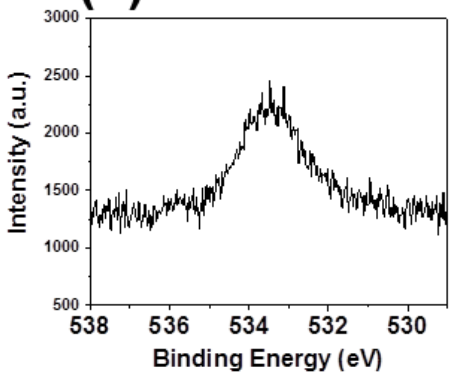

(f)

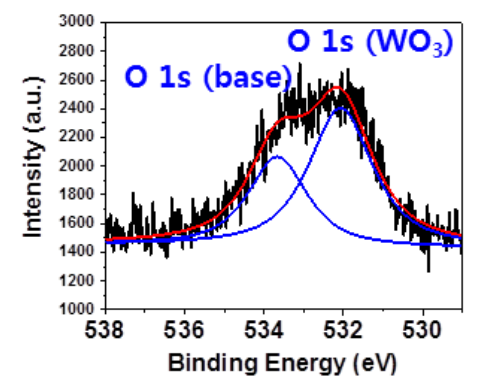

Figure S4. XPS spectra of pristine $\mathrm{WSe}_{2}$ and laser-exposed $\mathrm{WSe}_{2}$. (a) W 4f, (b) Se 3d, and (c) $\mathrm{O} 1 \mathrm{~s}$ peaks for pristine $\mathrm{WSe}_{2}$. (d) W 4f, (e) Se 3d, and (f) O $1 \mathrm{~S}$ peaks for laser-exposed $\mathrm{WSe}_{2}$. All XPS spectra were calibrated using the gold substrate $\mathrm{Au} 4 \mathrm{f}$ peak. The $\mathrm{W}^{6+} / \mathrm{W}^{4+}$ ratio in part (d) is $1.069(\sim 1: 1)$. In addition, the $\mathrm{Se} / \mathrm{W}$ ratios of $\mathrm{WSe}_{2}$ in pristine $\mathrm{WSe}_{2}$ and laserexposed $\mathrm{WSe}_{2}$ are 0.539 and 0.260 , respectively. 

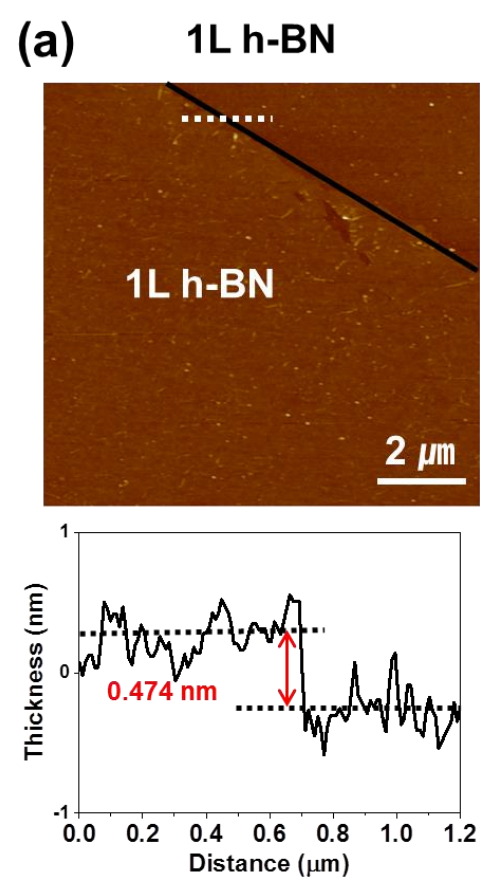

(b) 3L h-BN
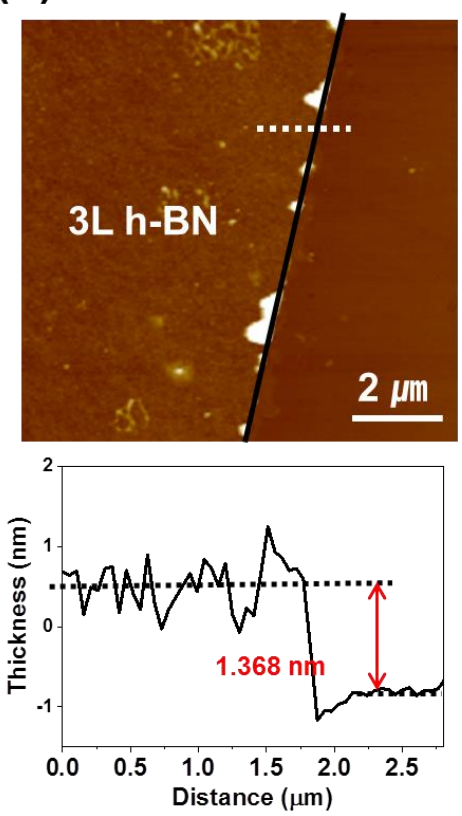

(c) $3 \mathrm{~L} \mathrm{h-BN/WSe_{2 }}$
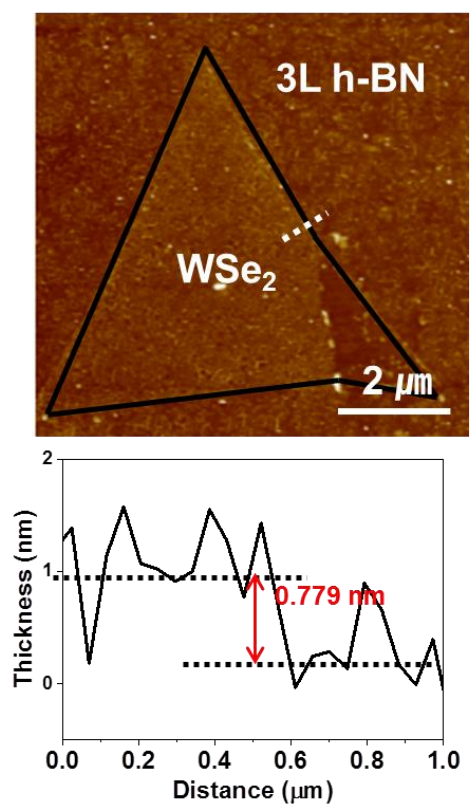

Figure S5. AFM image of (a) $1 \mathrm{~L}$ h-BN, (b) $3 \mathrm{~L} \mathrm{h-BN}$ and (c) $3 \mathrm{~L}$ h-BN/WSe 2 . 
(a)

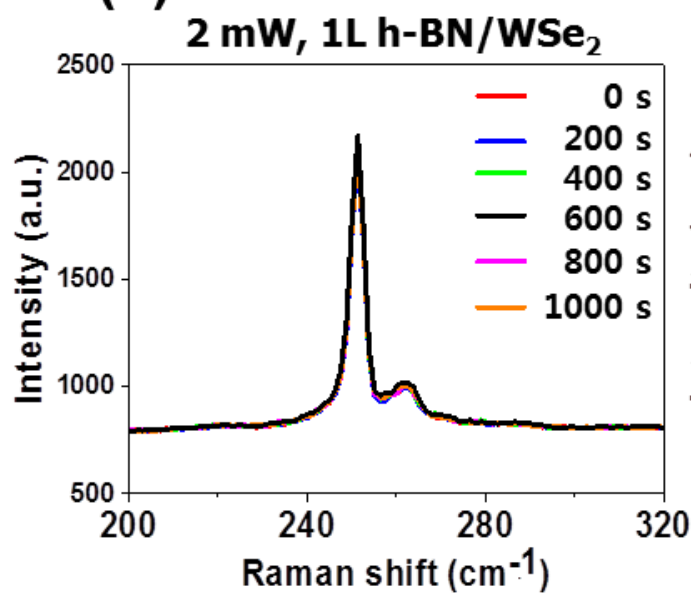

(c)

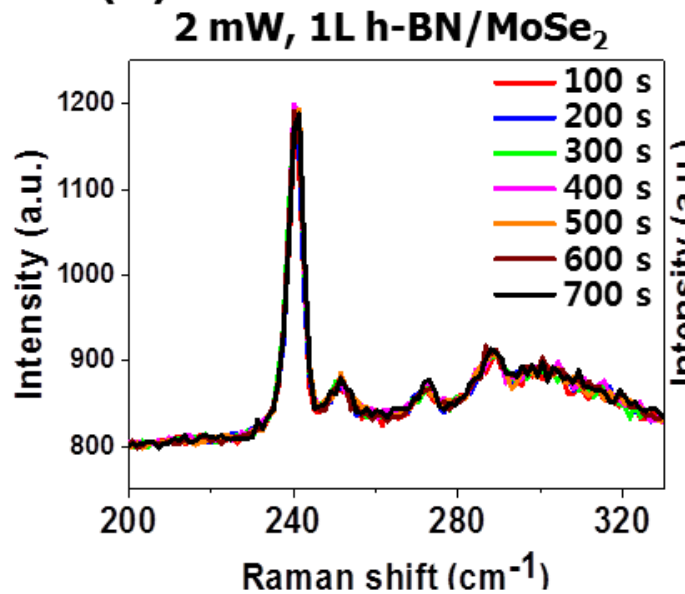

(b)

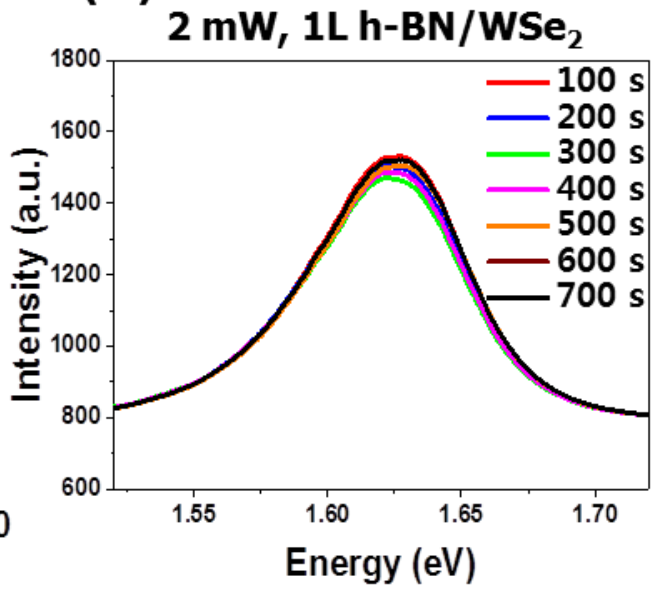

(d)

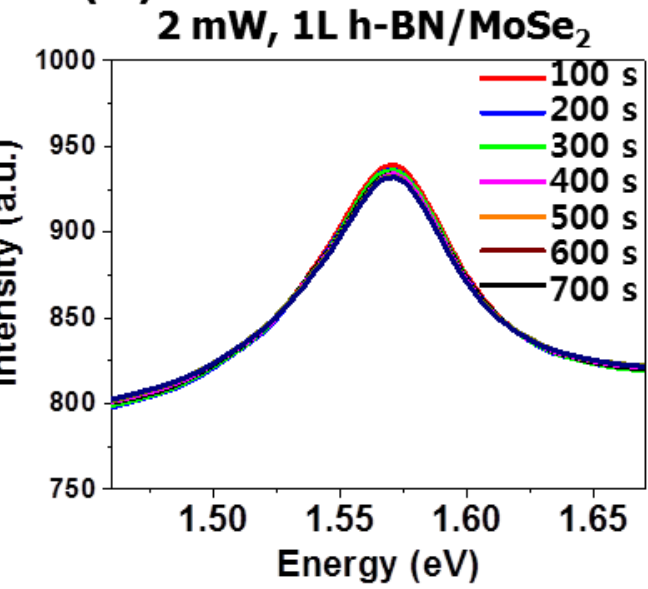

Figure S6. (a) Raman spectra and (b) PL spectra of $1 \mathrm{~L} \mathrm{~h}-\mathrm{BN} / \mathrm{WSe}_{2}$ at $2 \mathrm{~mW}$ recorded at various exposure times. (c) Raman spectra and (d) PL spectra of $1 \mathrm{~L} \mathrm{~h}-\mathrm{BN} / \mathrm{MoSe}_{2}$ at $2 \mathrm{~mW}$ recorded at various exposure times. 


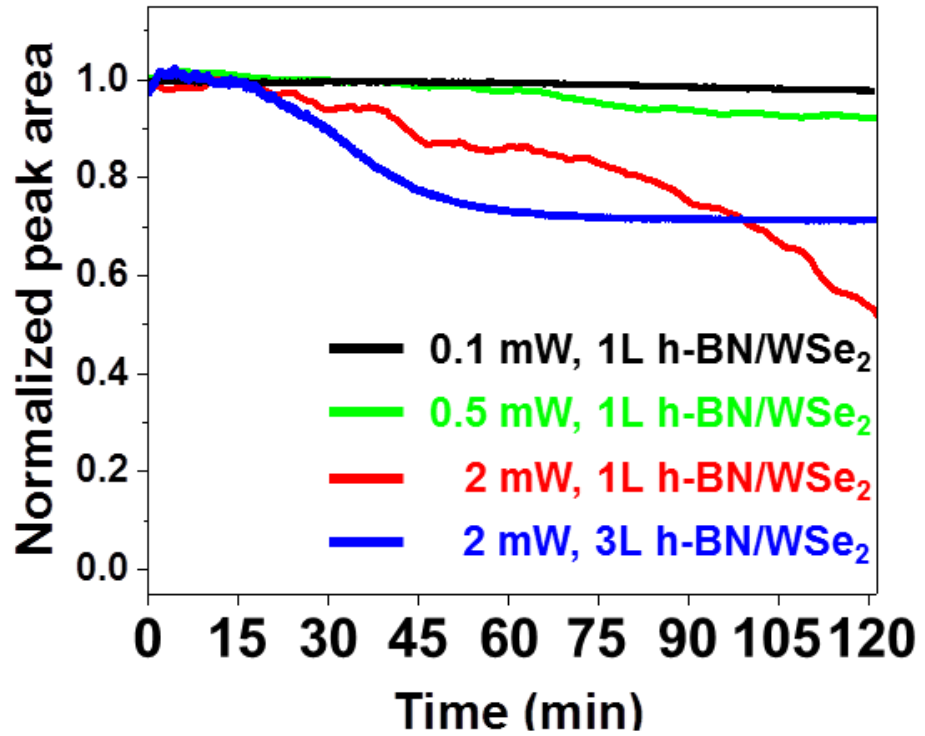

Figure S7. Variation in the PL peak areas of $1 \mathrm{~L} h-\mathrm{BN} / \mathrm{WSe}_{2}$ and $3 \mathrm{~L} \mathrm{~h}-\mathrm{BN} / \mathrm{WSe}_{2}$ at different laser powers as a function of the exposure time. 


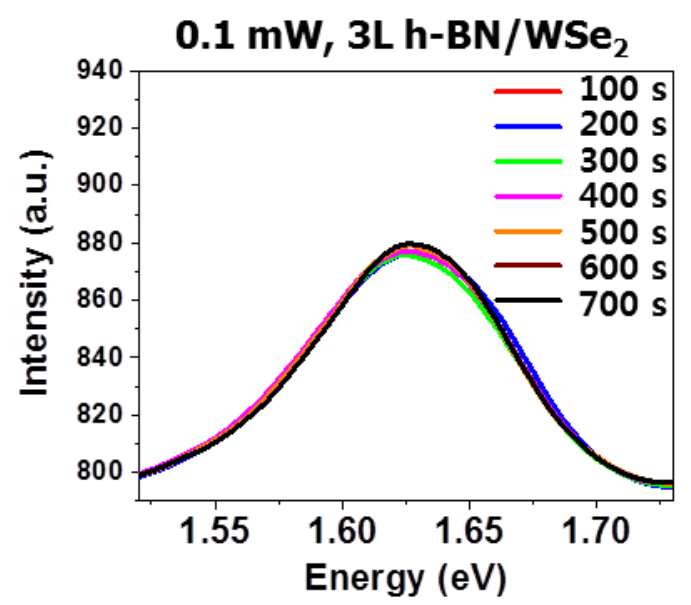

Figure S8. PL spectra of $3 \mathrm{~L} \mathrm{h-BN/WSe}{ }_{2}$ at $0.1 \mathrm{~mW}$ recorded at various exposure times in the presence of a water droplet. 
(a)

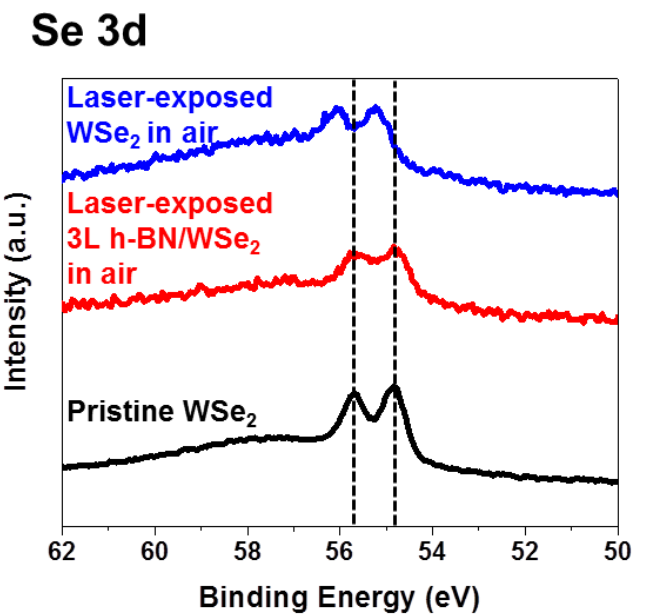

(b)

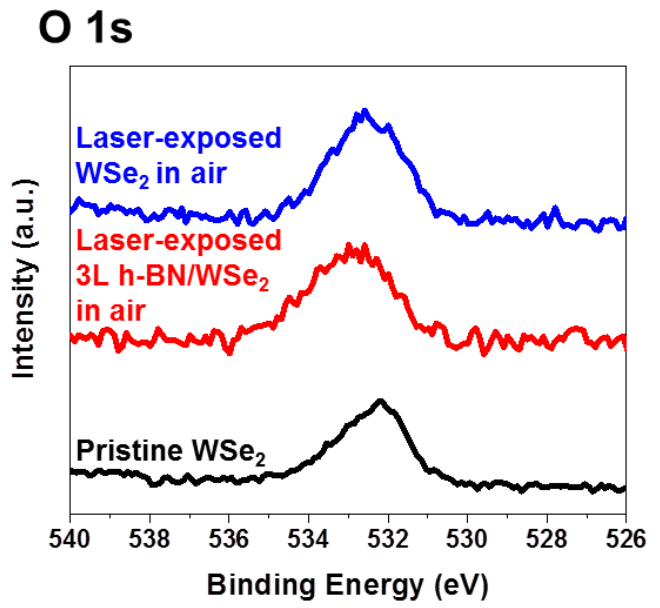

Figure S9. XPS spectra of pristine $\mathrm{WSe}_{2}$, laser-exposed $\mathrm{WSe}_{2}$ in air, and laser-exposed $3 \mathrm{~L} \mathrm{~h}$ $\mathrm{BN} / \mathrm{WSe}_{2}$ in air for the (a) Se 3d and (b) $\mathrm{O}$ 1s binding energies. XPS spectra were calibrated using the gold substrate $\mathrm{Au} 4 \mathrm{f}$ peak. 